\title{
Technology-Enhanced Knowledge Management Framework for Retaining Research Knowledge among University Academics
}

\author{
Patient Rambe, Mpho Agnes Mbeo \\ Central University of Technology, Bloemfontein, South Africa \\ prambe@cut.ac.za,mmbeo@cut.ac.za
}

\begin{abstract}
Given the challenge of retaining the research knowledge of an aging, experienced professoriate at South African Universities of Technology, institutions with a nascent tradition of scholarly research, this paper explores the feasibility of a technology-enhanced knowledge management framework for generating, sharing and retaining tacit research knowledge to leverage research outputs at the Central University of Technology (CUT), Free State, South Africa. Since digital trails of established-novice researcher interactions are left behind whenever they interact in online platforms, an examination of such interactions can provide insights into the sharing and transferring of tacit research knowledge from senior researchers to novices. This theoretical study draws on Nonaka and Takeuchi's Theory of Organisational Knowledge Creation, an emerging technology platform, SharePoint, mainstream literature and the authors' reflective experiences to develop a technology-enhanced knowledge management model. The paper argues that tacit knowledge can be assimilated from a comprehensive examination of the knowledge production interactions between senior academics and novices enabled by low threshold technology and collaborative sharing of content. This study's insights are relevant to Higher Educational Institutions (HEIs) struggling to create a sustainable culture of scholarly research and grow a new generation of competent researchers amid the attrition of senior academics and the prevalence of systemic blockages in knowledge transfer processes.
\end{abstract}

Keywords: Knowledge management, emerging technology, talent retention and research outputs

\section{Introduction}

Knowledge management (KM), which entails the management practices and processes that allow organisations to leverage their intellectual capital and create sustainable competitive advantage (Dumay, 2015), is becoming central to increasing research productivity and creating knowledge-based economies (Wallis, 2003; Rahnavard \& Mohammadi, 2009; Liebowitz, 2011; Talebi \& Galekandi, 2013). In spite of the fundamental economic benefits of knowledge management, Martins \& Meyer (2012) highlight the risk of losing people's tacit knowledge as one of the prime considerations in the development of knowledge retention strategies. In knowledge creating sectors such as higher education where senior academics are retiring, aging and exiting academia at a pace faster than their rate of replacement by less experienced, junior academics, the demands for intergenerational transfer and retention of tacit research knowledge have been acute (Durst \& Ferenhof, 2014; Rambe \& Mlambo, 2014; Burmeister \& Deller, 2016). Notwithstanding the fundamental importance of tacit knowledge retention in view of the aging and shrinking of the skilled research workforce, Burmeister \& Deller (2016) highlight that research on tacit knowledge transfer in organisations is scarce, and an integrated conceptual framework for promoting tacit knowledge transfer and retention is yet to be developed. In view of the tragedy that when valuable employees retire, valuable knowledge is lost if there are no effective knowledge management processes in place to prevent it (Burmeister \& Rooney, 2015), this study seeks to develop a technology-enhanced knowledge management framework for retaining research knowledge at the Central University of Technology, Free State (CUT) in South Africa.

The louder call for effective knowledge management strategies in higher education manifests in Baban's (2007) emphasis on (1) the development of mechanisms to acquire, select, organise and retrieve knowledge, both within and outside higher education, and (2) the generation of management practices to transfer knowledge across the organisation, with a special attention to the management of tacit knowledge. To the extent that tacit knowledge is profoundly unique but difficult to understand and transfer, there is no doubt that tapping into such knowledge can contribute to the improved differentiation of the organisation and the leveraging of its competitive advantage. Therefore, Baban's (2007) two considerations are critical to the South African higher education institutions (SAHEIs), which consider knowledge production and retention as critical components of their reputation by ranking race. For instance, traditional university ranking 
systems' exclusive focus on areas that carry the greatest ranking weight, such as scientific research performance (Ntshoe \& Selesho, 2014) has pushed South African universities to jostle for national and international recognition and status through leveraging their research publication outputs, the number of doctoral graduates and National Research Foundation (NRF) rated researchers. With this 'reputation race' in which institutions strive to leap higher the university ranking charts yearly (Richardson, 2011) comes an obligation for universities not only to retain prolific, aging professoriate but also develop sustainable knowledge management models that embrace the intergenerational transfer of tacit research knowledge.

Although there is growing consensus on the capacity of emerging technologies (ETs) to enhance and leverage research knowledge management (Rao, 2002; Dave, Dave \& Shishodia, 2012; Pande, Yavatmal, Shelodkar \& Khobragade, 2013; Dumay, 2015; El Badawy, Marwan \& Magdy, 2015), the ideal nature of the knowledge retention process is yet to be fully understood (Burmeister \& Deller, 2016). While the field of knowledge retention [drawing on ETs] is only beginning to emerge (Martins \& Meyer, 2012), the call to exploit low cost, low threshold ubiquitous technologies to transfer and retain knowledge has never been louder (Rambe \& Mlambo, 2014; Bozalek, Gachago \& Watters, 2015; Ng'ambi \& Bozalek, 2015). For this reason, this research addresses the following research questions:

- What institutional mechanisms have been employed by the Central University of Technology (CUT), Free State to enhance the retention and transfer of tacit research knowledge from senior academics to a new generation of emerging researchers?

- What are the current constraints of this university's research knowledge retention and transfer strategies?

- How can emerge technologies (e.g. SharePoint) be harnessed to enhance the retention and transfer of tacit research knowledge from senior academics to a new generation of emerging researchers?

- How can a technology-enhanced knowledge management framework be constituted to foster the transfer of tacit research knowledge from senior academics to the young generation of academics at the Central University of Technology, Free State?

The rest of this paper is organised as follows: the problem statement is rendered, the research background and a literature review are presented, a conceptual framework is then developed, and the authors' reflections founded on the mainstream knowledge management and ET literature and personal experiences are rendered, implications for future studies are given and a conclusion is granted.

Problem Statement: Knowledge management literature has highlighted the need for knowledge generation, transfer and retention in particular, the need to devise proactive measures to address the potential acute shortages of research leadership in higher education worldwide in general, and in SAHEIs in particular (Levine, 2008; Carman, Leland \& Wilson, 2010; Robinson, Carrillo, Anumba \& Patel, 2010; McNair, Duree \& Ebbers, 2011). These fissures in research leadership are exacerbated by an apparent disjuncture between the retention rate of senior academics (e.g. full professors, associate professors and senior researchers with researcher experience) and their replacement by a new generation of staff with nascent experience and research competencies as well as other systemic blockages that constrain knowledge transfer and retention. According to Thomas (2009) the paucity of higher educational leadership can be a consequence of early retirement, mid or late career changes or outsourcing, leading to persistent gaps in the retention of research knowledge. At the Central University of Technology (CUT), Free State, where a small cohort of the professoriate comprising 16 associate professors and 11 full professors exists (De Jager, 2014), the progression of junior staff to professorship has been derailed by the lack of a strong research culture at the institution. For instance, out of a total employ of 276 permanent academic staff members, there were only 6 NRF rated researchers in 2014 (De Jager, 2014). Similarly, the number of accredited articles in comparison with permanent staff (excluding staff involved with post-graduate studies and junior lecturers) in the faculty of Management Sciences, which is ranked as one of the most research productive faculties at CUT, was below ten units for the four quarters of the year 2015 (Chipunza, 2015).

CUT has witnessed numerous strides in its research agenda over the years. For example, it generated 55.02 journal credit units, 13.02 published conference proceeding units and 0.44 scientific book units in 2014 and received the NRF Excelleration Award for attaining the most improved research performance in recent years (Research and Innovation Report, 2014). In spite of these laudable research achievements, some systemic 
fissures that point to constrained knowledge generation and transfer capacity still remain. In fact, the aforementioned 2014 research outputs represented a weighted output of 0.24 units per academic staff member (Research and Innovation Report, 2014), a clear demonstration of the skewed distribution of knowledge production of the staff members at this university. This possibly implies the concentration of prolific research production among senior, experienced academics and the limited contribution of junior academics at the institution. In view of the need to grow the number of publication outputs to the expected Department of Higher Education and Training's (DHET) norm of 75\% by 2020 (the current norm is 1.1 credit output-unit per full-time academic staff at CUT) (Lategan, 2015), the fact that a sizable number of permanently employed academic staff have not published an article suggests the prevalence of "juniorisation" of research at the institution. The low ratio of research output to academic staff members suggests some systemic institutional blockages and personal constraints in the existing knowledge transfer models at this institution.

Furthermore, the potential research experience gap between the current, retiring leaders (senior researchers and professors) and emerging researchers expected to fill the vacated positions at CUT is very disturbing (Joshi, Dencker, Franz \& Martocchio, 2010; Linder \& Wald, 2011, Mbeo and Rambe, 2016). It demonstrates the lack of a solid research tradition at Universities of Technologies (UoT) that enables intergenerational transfer of knowledge. Since UoTs were primarily designed to offer sectoral knowledge derived from specific occupational, industrial sectors on the one hand, and specialist disciplines on the other, their primary foci and specialisations have traditionally been teaching and the conduct of applied research required by industry and employers (Ntshoe \& Selesho, 2014) rather than the production of scholarly research-based knowledge, the domain of traditional research-intensive universities. A clear manifestation of this limited tradition of cutting edge research and limited knowledge transfer across academic generations manifests in strident efforts of UoTs such as CUT to transform their research staff into more seasoned academics. As Lategan (2015) observes, CUT is striving to decrease the "juniorisation" of its institutional research system in favour of "seniorisation" through: increased academic staff participation in research outputs (primarily award of research grants, publications, completed postgraduate studies and rated researchers) and studies towards higher qualifications in their disciplines.

Problem background: The challenge of developing an appropriate technology-enhanced framework for the retention of tacit research knowledge can be approached from the perspective of national development imperatives and national funding policies for South African universities. These are inter alia the following: The national pressure on higher education to increase research productivity, to contribute immensely to the knowledge economy and social innovations, the research performance-based funding policy, which appear to be inconsistent with the differentiated higher education system, and the compulsive elements of world ranking of universities. These critical points are elaborated in subsequent sections.

Pressure to contribute to increased research productivity to meet national development goals: More than half a decade after the abolition of apartheid in South Africa, strong manifestations of valuing the production and retention of research knowledge had begun to emerge in the country's higher education landscape. By the early 2000s, research and development had already become the mainstay of higher education in the country (Waghid \& Le Grange, 2003) as evidenced by the increased pressure to secure research grants, obtaining [research] rating from the National Research Foundation (NRF) and South African academics' need for promotion, which prized academic research above teaching and community service (Le Grange, 2003). Since then, the research productivity dimension of universities seems to determine the performance, excellence and reputation of institutions, and the standing of academic staff through securing of NRF rating (Ntshoe \& Selesho, 2014).

The promotion of research productivity at South African universities is also informed by the advancement of the national development agenda. Perhaps, the South African government's first bold emphasis on research productivity was laid in the National Plan on Higher Education (NPHE), which stressed the importance of sustaining current research strengths of universities, promoting research and knowledge outputs required to meet the development needs of the nation (NPHE, 2001). This national development thrust of research performance is substantiated in the White Paper for Post-School Education and Training (2013), which focuses on "growing research and innovation, improving the quality of research, ensuring coherence of the 
policy frameworks guiding these areas across the higher education, research communities and strengthening particular areas identified as important for national development." The need for high quality research that meets developmental imperatives is also alluded to in future policy documents. The 2015 Research Output Policy of the South African Department of Higher Education and Training (DHET) stipulates its intention to encourage research productivity by recognising and rewarding quality research output at public higher education institutions in pursuit of national development goals (DHET, 2015).

The emphasis on research productivity has also been voiced at institutional levels. For instance, the then Vice-Chancellor of the Central University of Technology, Free State, highlights how this university has embraced research and innovation as a key driver in addressing policy imperatives and socio-economic challenges of the communities it serves (Mthembu, 2014). Consistent with this recognition of the importance of expanding research outputs, the university has witnessed a $16.2 \%$ growth in publication outputs for the years 2012-2013 (Mthembu, 2014). In spite of these significant strides, the disaggregation of this growth in research output per academic staff member for the same year is far from commendable. For example, the total of 110 or $71 \%$ publications produced at CUT in the $2012-2013$ year was produced by 274 academic staff members representing 0.565 output units per full-time academic staff member. More so, the projected growth target in research outputs per academic staff member for the year 2020 target of 0.75 (De Jager, 2014) suggests a disproportionate contribution by senior academics exclusively compared to junior staff. More so, despite the adoption of the CUT Research and Development Plan 2014 - 2020, the policy on Strategic Research Clusters (i.e. Research Centres, Units and Groups) and research mentor-mentee programmes such as Stars of Academe and Research (SoAR), there is no compelling evidence of differentiation of research output on the basis of quality (e.g. publications in high impact journals, improved citation index of authors, increase in the number of National Research Chairs from NRF) at the institution. In view of the foregoing arguments, the need for mechanisms to transfer tacit research knowledge from the small pool of experienced professors to junior academics cannot be overemphasised.

Differentiated higher educational system and performative nature of university funding: Universities of Technology are a consequence of the major reconfiguration of the higher education landscape, which took place from 2004 onwards. Through a process of mergers and re-designations, South Africa's 36 higher education institutions ( 21 traditional universities and 15 technikons) were trimmed down to 23 - comprising 11 traditional (some of which were merged with others), 6 comprehensive universities (arising from mergers between a traditional university and a technikon), and 6 Universities of Technology (created from 11 unmerged technikons) (Du Pre, 2010). While some of the knowledge management challenges are a consequence of this merging of differentiated educational systems with different research production ethos, capacities and practices and varying resource constraints, other challenges arise from the paucity of tacit research knowledge production and retention strategies of individual institutions especially those of UoTs.

To further compound the challenge of merging institutions with different research traditions, the funding formula of the DHET does not seems to differentiate high from low impact publishing through considering the reputation of book publishing houses, the impact factors of journals and conferences. For instance, not only does government funding policy fail to differentiate between 'high' or 'low' impact journals; citation indexes and other relevant research quality measurements, it also does not differentiate between types of output. For instance, all journal outputs receive the same level of subsidy irrespective of whether they are published internationally or locally (DHET Research Outputs Policy, 2015). We, therefore, argue that to the extent that the incentive system erroneously prices research productivity at the expense of publication quality and impact, it discourages academics' aspirations to publish in high impact journals with more rigorous peer review system and research quality considerations. This problematic incentive system further undermines the culture of scholarly research and may compromise the intergenerational transfer of seasoned research expertise to emerging scholars.

The digression of world ranking of universities: While UoTs have certain key distinguishing features, missions and mandates, the conspicuous emphasis on research productivity seems to have distorted these imperatives and compelled these universities to jump onto the research gravy train. The South African Technology Network (SATN, 2008) observes that among other considerations, UoTs were created to:

- Provide technology-focused programmes, with undergraduate career-oriented education and 
technological competence as their main attributes;

- Render applied research and innovation in and through technology and technique in strategic areas, with the attributes of technology transfer; and

- Generate entrepreneurial and innovative ethos, with the creation of an enabling environment for developing commercial ventures and student entrepreneurship.

Although these considerations may not necessarily conflict with the "publish or perish" mantra which the world ranking of universities has created, this over-emphasis on publications has pushed UoTs to elide their broader mandates in pursuits of research productivity. The consequences of the university ranking's emphasis on research productivity are the homogenisation of the university (Neave, 1996; Ntshoe \& Selesho, 2014) and failure to sufficiently represent and capture a diverse range of issues, such as student satisfaction within these institutions (Richardson, 2011). The main weakness of traditional ranking of universities are that: (i) ranking focuses exclusively on whole institutions (ignoring internal variance); (ii) the focus is on comprehensive research universities ignoring the diversity of missions and structures [of non-traditional universities]; (iii) ranking concentrates on traditional research productivity, impact and aggregation of performance into composite overall indicators (Federkeil \& Westerheijden, 2009). We extend Federkeil \& Westerheijden's (2009) views by arguing that the intergenerational knowledge transfer component may be compromised by the UoTs' relentless pursuit of research productivity to improve their world rankings.

We argue that the reputation rivalry created by the ranking of universities has digressed UoTs from their main mandate of vocational education. Therefore, UoTs' pre-occupation with the development of vocational/professional education; technological capabilities as important as cognitive skills (Du Pre, 2009) has been sacrificed in pursuit of the publication agenda. The reputation frenzy of South African UoTs has also tempted them to pursue the values of research intensive, traditional universities. This coercive isomorphism manifests in powerful organisations' (e.g. traditional research-intensive universities) application of pressure and imposition of structural forms and/or practices on weaker organisations (e.g. UoTs with a nascent research culture), pushing the weaker institutions to comply with the forms, rules and norms of the stronger organisations (Van Vught, 2007). The traditional research-intensive universities with a strong tradition of research, long track record of publishing in leading journals and diversified funding models tend to exert their influence on the drafting and development of higher education policy in South Africa and hence, trigger an isomorphism that constraints the capacity of universities with a nascent research trajectory to exercise institutional autonomy and chart their own destiny. This argument buttresses Ng'ethe, Subotzky \& Afeti's (2008) claim that newly formed universities are likely to model themselves around the practices of older and more established institutions.

\section{Theoretical Framework}

Nonaka and Takeuchi's Theory of Organisational Knowledge Creation: Nonaka and Takeuchi (1995) proposed a theory to explain the phenomenon of organisational knowledge creation and retention. They defined organisational knowledge creation as "...the capability of a company as a whole to create new knowledge, disseminate it throughout the organisation, and embody it in products, services and systems." Nonaka and Takeuchi (1995) argue that knowledge is created initially by individuals and such knowledge becomes organisational knowledge through a process described in Figure 1. The focus of the current study is not on organisational knowledge per se but rather on how tacit research knowledge can be transferred from senior experienced research academics to junior staff as well as its retention among such staff.

The Theory of Organisational Knowledge Creation describes two dimensions of organisational knowledge creation namely the epistemological and ontological. On the epistemological level, the authors recognise two types of knowledge-tacit and explicit. Explicit knowledge is the knowledge that can be written down and is easily transferred from one person to the next. Senior researchers may communicate disciplinary content and subject matter such as constructs and concepts through transmission processes such as direct teaching, mentoring, simulations and coaching. To the contrary, tacit knowledge is more difficult to articulate because it is often embedded in individual experiences. Such knowledge may be assimilated through junior researchers' imitation of the research repertoires of seasoned researchers and close reading of their informal writings in informal spaces (e.g. blogs and wikis) to interpret and make inferences about such writings. The 
ontological dimension ranges from the individual level to team, group, organisation level and beyond. The current study is preoccupied with knowledge retention and transfer that unfolds between individuals and groups - that is between the experienced knowers (that is, seasoned academics and researchers) and the research novices (that is, junior researchers) at CUT.

With regard to the knowledge generation and transfer process, Nonaka and Takeuchi (1995) further assert that a spiral emerges when the interaction between tacit and explicit knowledge is elevated dynamically from a lower ontological level to higher levels. The four modes of knowledge conversion create a spiral through which knowledge is transformed from one type to another. These models include socialisation (from tacit to tacit knowledge), externalisation (from tacit to explicit knowledge), combination (from explicit to explicit knowledge), and internalisation (from explicit to tacit knowledge). Junior academics can be socialised into leading research productivity through informal conversations with senior academics on important subjects in their disciplinary fields or through accessing the informal writing of senior academics in informal spaces such as their personal blogs, wikis, and virtual learning communities. Externalisation processes can take the form of senior academics' engagement with their personal experiences, anecdotes, conventional wisdom, lay and mainstream literature in preparation of scholarly papers to deliver at seminars, inaugural lectures and keynote addresses and the direct mentoring of junior staff informal learning spaces. Combining knowledge may arise from formal modes of knowledge delivery such as: (1) a senior academic's use of a lecture to teach the concepts s/he wrote in her scholarly book or article, and (2) demonstration of a clinical procedure drawing on established/ conventional standard operating procedure. Internalisation may involve drawing on a seasoned academic' constructs or concepts (explicit knowledge) to write up a concept paper or a nonscholarly article (tacit knowledge).

Figure 1: Knowledge spiral on epistemological level

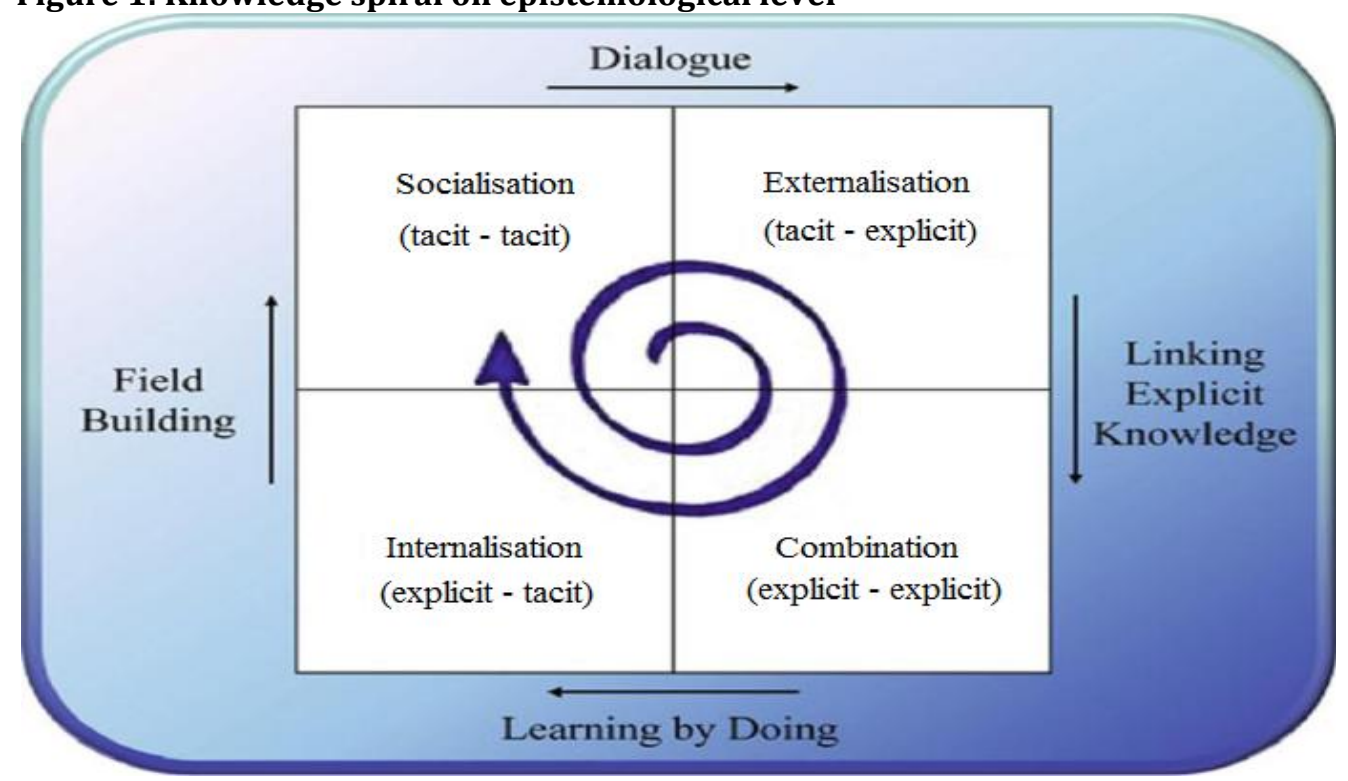

Source: Wilde, 2011

Nonaka and Takeuchi (1995) drew extensively on the existing body of knowledge on organisational knowledge creation and a collection of case studies of multiple Japanese organisations to develop their Theory of Organisational Knowledge Creation. Figure 1 summarises the knowledge creation and retention process. From a process perspective, knowledge creation and retention in organisations entails the following:

- From tacit to tacit: occurs when an experienced researcher exchanges knowledge with a novice in face to face communication.

- From tacit to explicit: generating new knowledge by combining existing knowledge. For instance, an organisation's director of finance collects financial information from different parts of the organisation to produce financial reports.

- From implicit to explicit: Developing experiences, opinions and comments so that others can use 
them.

- From explicit to implicit: implicit knowledge occurs when it is internalised in staff and results in the development of their own knowledge.

\section{Literature Review}

Knowledge transfer and retention: In view of this paper's focus on developing a model for knowledge transfer and retention, this section of the study is preoccupied with knowledge transfer and retention. The concepts of knowledge transfer and retention are linked to knowledge loss occasioned by experienced employees' departure from organisations. As Phaladi (2011) observes, when key employees leave the organisation, expert knowledge leaves with them. Accordingly, this challenge of surging retirements is tougher for organisations with a limited research culture such as that of CUT. This is because it takes a protracted duration (e.g. years or generations) to transfer critical knowledge developed through many years of experience from highly experienced researchers to novice researchers. For Carlie \& Rebentisch (2003), knowledge transfer is an area of knowledge management concerned with the movement of knowledge across the boundaries created by specialised knowledge domains. It is a process of identifying and retaining research knowledge that already exists in the organisation, acquiring as well as applying it to enhance organisational performance and sustainability in both short-term and long-term planning (Phaladi, 2011). Yet knowledge transfer is deeply implicated in knowledge retention and cannot be divorced from it. Literature alludes to the action oriented and performance-based nature of knowledge retention (Kirsch, 2008; Liebowitz, 2008). For instance, Kirsch (2008) argues that knowledge retention focuses on the critical knowledge at the risk of loss, prioritises such knowledge based on the potential knowledge gaps and their impact on overall organisational performance, and then develops actionable plans to retain such knowledge. One of the key reasons for enhancing knowledge retention is to grow the institutional memory of the organisation (Liebowitz, 2008), by allowing employees to learn from past successes and failures to ensure positive research results.

Knowledge retention and transfer as forms of knowledge management cannot be fully understood without recourse to types of knowledge, and hence it is necessary to make a distinction between explicit and tacit knowledge. Explicit knowledge is the knowledge that can be written down or articulated through formal language such as manuals, procedures, guidelines or reports. Tacit knowledge is the knowledge that cannot be written down, is difficult to articulate through formal language and is embedded in an individual's experiences as well as their values or emotions (Rai, 2011). Notwithstanding such variations in definition, both types of knowledge are essential to the growth of any organisation (Ngai \& Chan, 2005) as they provide a framework through which knowledge can be transferred. Literature emphasises how distinguishing between the two categories and even transcending such a distinction allows an organisation to be innovative, efficient, competitive and enduring (Chen, 2004; Rhodes, Hung, Lok, Lien \& Wu, 2008; Rowe \& Widener, 2011). Overall, tacit and explicit knowledge are consequences of knowledge transfer and knowledge retention, processes that are mutually interdependent.

Knowledge transfer and knowledge retention are components of a protracted process of knowledge management. To the extent that knowledge is the most important strategic resource of a firm and has enormous effects on organisations' competitive advantage (Kang, Rhee \& Kang, 2010), firm success in the $21^{\text {st }}$ Century is intractably connected to existing knowledge and creating new ones continuously in response to rapid changes in society (Baban, 2007). Therefore, a holistic approach to knowledge management is more informative than an examination of the individual distinct processes of knowledge management. At the core of knowledge management is to transform individual knowledge into organisational knowledge through acquiring, sharing, storing, disseminating, exploiting and applying knowledge innovatively. Knowledge management also assists higher education managers in their managerial and administrative efforts to facilitate the acquisition, creation, storage, sharing, diffusion, development, and deployment of knowledge by individuals and groups (Zheng, Yang \& McLean, 2010). However, an organisation's knowledge management activities should not be limited to knowledge creation and dissemination but to activities related to knowledge retention as well (Durst \& Ferenhof, 2014). Therefore, the entire life of the knowledge management (KM) process should be considered to better understand KM activities in HE. 
Knowledge transfer, retention and research outputs: As already articulated, knowledge retention is about "maintaining, not losing, knowledge that exists in the minds of people (tacit knowledge, not easily documented) and knowing (experiential action manifesting in behaviour) that is vital to the organisation's overall functioning" (Martins \& Meyer, 2012). Therefore, knowledge retention entails strategies for retaining knowledge already generated or about to be generated within the organisation to ensure its continued existence and improved productivity. Similarly, knowledge transfer involves the processes of capturing, documenting and sharing acquired explicit and tacit knowledge for re-use in similar or varied contexts. In view of the irony between the increasingly critical importance of knowledge to organisational productivity and the inevitability of knowledge loss due to the massive wave of retirements of members of the baby boomer generation (Beazley, Boenisch \& Harden, 2002; Burmeister \& Deller, 2016), the need to retain and transfer knowledge cannot be overemphasised. This need is dire in the South African higher education, where it is considered to take approximately two decades for a doctoral graduate to be groomed into a seasoned professor/ highly experienced researcher (Mangcu, 2014; Price, 2016). Unfortunately, extracting knowledge from these seasoned academics to make it available to novices within the organisation is not an automatic process (Calo, 2008) due to the variability of personal traits, contexts and organisations in which knowledge transfer occurs. That said, to the extent that knowledge retention and transfer can help organisations to reduce the danger of knowledge leakage or loss (Andersen, 2012), addressing the challenge of knowledge loss is critical to increasing the competitive advantage of smaller institutions such as CUT.

In essence, key enablers for successful knowledge management in the higher education institutions are knowledge transfer and retention, which are founded on sharing, collaborating and contributing to explicit and tacit knowledge. The transfer and retention of research knowledge is particularly urgent for CUT, where a small, emerging generation of research active academics operates in an academic environment marked by the drift of the aging professoriate. The capturing, documenting and transferring of existing and new knowledge in the research innovation chain is not only critical to the sustainable increase of peer-reviewed books, DHET accredited articles and conference proceedings, research patents, postgraduate student graduations and internationalisation of the research but also the inter-generational sharing of research expertise at CUT. Given the importance of knowledge in advancing organisational competitiveness; organisational processes for transferring knowledge from well-seasoned employees to the inexperienced have to be devised (Bussard, 2013).

Institutional mechanisms for knowledge retention and transfer and their associated constraints at CUT: Vision 2020 Strategic Plan, Research and Development Plan 2014-2020 and Technology Innovation Plans are some of the strategic research documents CUT has designed and implemented to reposition the university as a key player in the knowledge economy, increase its research outputs and introduce innovations which improve the well-being of less privileged communities respectively (Mthembu, 2014). The implementation of the CUT Research and Development Plan 2014 - 2020 manifests in inter alia, the realignment of research entities with new research priorities, and the development of an institutional policy on research centres, units and groups, the rolling out of ten research support programmes for the benefit of staff and postgraduate students, and increasing the research capacity of the institution (De Jager, 2014). CUT has also developed a couple of interventions for dealing with the transfer of knowledge from senior academics to junior academics. These include mentorship programmes such as Scholarship of Teaching and Learning (SoTL), Stars of Academe and Research (SoAR), and Talent Management Strategy and the strengthening of the research collaboration with the University of the Free State, a neighbouring traditional research-intensive university.

Although it is early to understand the full impact of these recently developed research interventions, some of their strides manifest in the following: increased publication outputs, postgraduate student completions, academic staff with doctoral degrees, and a slight increase in the number of NRF rated researchers. For instance:

- Thirteen doctoral degrees were awarded in 2014 compared to the three awarded in 2013.

- In 2013, the university had 55.02 journal credit units, 13.02 published conference proceeding units and 0.44 scientific book units.

- $72 \%$ of the 2014 publications target was achieved towards the end of 2014.

- An increase in NRF rated researchers from six in 2014 to nine in 2015.

- The generation of R8.5 million from external funding for the year 2014 in addition to the R8.7 million 
external funding availed for the year 2013 (Research and Innovation Report, 2014).

In spite of these significant research developments, multiple research challenges still remain at CUT. For instance, the aforementioned academic output for 2013 represented a weighted output of 0.24 units per academic staff member (Research and Innovation Report, 2014). In view of the 107 academic staff holding doctorates at the institution in the year 2013 (Progress Report on Academic Plan, 2014), we infer that the increase in research productivity at the institution is attributed to a handful of prolific experienced researchers across the different faculties. This means that the institution harbours a sizable number of research inactive academics. Perhaps, this low research profile can be interpreted as a lack of effective mechanisms for transferring research knowledge from senior academics/researchers to emerging academics and the reluctance of senior academics to share their research expertise. More so, the sluggish growth in the number of NRF rated researchers due to retirements, resignations and exits is a cause for concern. For instance, between the years 2013, 2014 and 2015, their numbers fluctuated from 7 to 6 and then 9 respectively (De Jager, 2014). The growth in external funding can also be attributed to the individual efforts of a small number of experienced academics, suggesting the lack of transfer of research grant proposal writing skills.

Emerging technologies to enhance the retention and transfer of research knowledge: Emerging technologies (ETs), are those new or evolving technologies that can be used to enhance teaching, learning, research and creative inquiry, culminating in the generation of new knowledge (Johnson, Smith, Willis, Levine \& Haywood, 2011). To the extent that the adoption of ETs is on the rise in the higher education sector worldwide, there is a growing consensus that such technologies may be a panacea to the knowledge management woes which research based and knowledge-creating institutions are entrapped in (Dave, Dave \& Shishodia, 2012; Bozalek, Ng'ambi \& Gachago, 2013; Pande, Yavatmal, Shelodkar \& Khobragade, 2013; El Badawy, Marwan, Magdy, 2015). Emerging technologies such as social networking sites, content repositories, learning management systems and virtual games, are contributing to the digitisation of knowledge creation processes, changing the structure of knowledge management processes, improving the efficiency and effectiveness of knowledge work processes, improving access to information at tweak speed and increasing the competitive advantage of research institutions (Gates, 1999; Rotman, 2013; El Badawy et al., 2015). In spite of the acknowledegment of ETs' capacity to foster knowledge management, the actual impact of such technologies on knowledge transfer and retention is yet to be fully comprehended and realised.

While the decreasing cost of access to content and the concomitant increased availability of ETs are creating new possibilities for the transformation of pedagogical and social practices in higher education (Bozalek, Gachago \& Watters, 2015), good examples of ET use for knowledge transfer and retention remain speculative and under-explored in mainstream management literature. The New Media Consortium examined the view of experts to understand how emerging technologies would impact on creative scholarly inquiry (an example of knowledge management) in a variety of Latin American Higher Educational Institutions. One of its key findings that resonate with knowledge management was that most academics are not using new and compelling technologies for organising their own research, and metrics of evaluating their research lagged behind new scholarly forms of research, authorship, and publishing (Johnson et al., 2011).

The under-researched nature of ETs for knowledge management creates a chasm in our in-depth understanding of the critical and relevant processes of knowledge transfer and retention. To the extent that most ETs were invented long after the boomer's generation (those aged between 50 and 70) had progressed in their professions without them, this generation may harbour negative perceptions on the uptake, appropriation and implementation of these technologies for knowledge management (Burch \& Strawderman, 2014). That said, the growing family of ETs such as collaborative platforms (wikis, blogs), digital content repositories (e.g. Google docs, Google drive, Dropbox), academic sites (such as Researchgate, Academia.edu, Linked-in) and application software (such as SharePoint) are indispensable knowledge management platforms upon which effective $21^{\text {st }}$ Century researchers and academics depend on for knowledge appreciation, generation, enactment, documentation, retention and transfer.

An ET such as SharePoint is a useful collaborative knowledge creation and sharing tool for senior academics at CUT, an institution under pressure to retain and transfer its research knowledge to emerging academics, 
amid the aging, retiring and exiting of its experienced academics. SharePoint has potential to grow the institutional memory of the organisation through its provisions of:

- A platform for experienced academics to generate and store content and knowledge (that is, a knowledge repository).

- Interactive interfaces that allow novices' individual reflection and senior researchers-novices' collaborative interaction (that is, meaningful engagement).

- Textual archives that retain trails of previous conversations between research experts and expertnovices, which other novices can access in future to augment their memory (that is, digital footprints).

- Open learning of novices in connected individual environment (that is, a personal learning environment).

By providing a connected interactive environment that allows for individual reflection and collaborative networking of research processes between experienced researchers and novices, SharePoint serves as an effective platform for enhancing knowledge transfer and retention. In this manner, novices can learn from past successes and failures of experts to ensure positive results. Learning from experts could help novices avoid going down the wrong paths or reinventing the wheel (Liebowitz, 2008).

\section{Proposed conceptual framework}

Consistent with the intention of this study to investigate the feasibility of a knowledge management (KM) model for the retention and transfer of tacit research knowledge from senior academics to junior academics at CUT, Free State, we argue that SharePoint enables six knowledge creation processes namely knowledge appreciation, knowledge enactment and documentation (i.e. knowledge creation), knowledge sharing, knowledge transfer and retention (See Figure 2).

Figure 2: ET-enhanced model for knowledge generation, transfer and retention

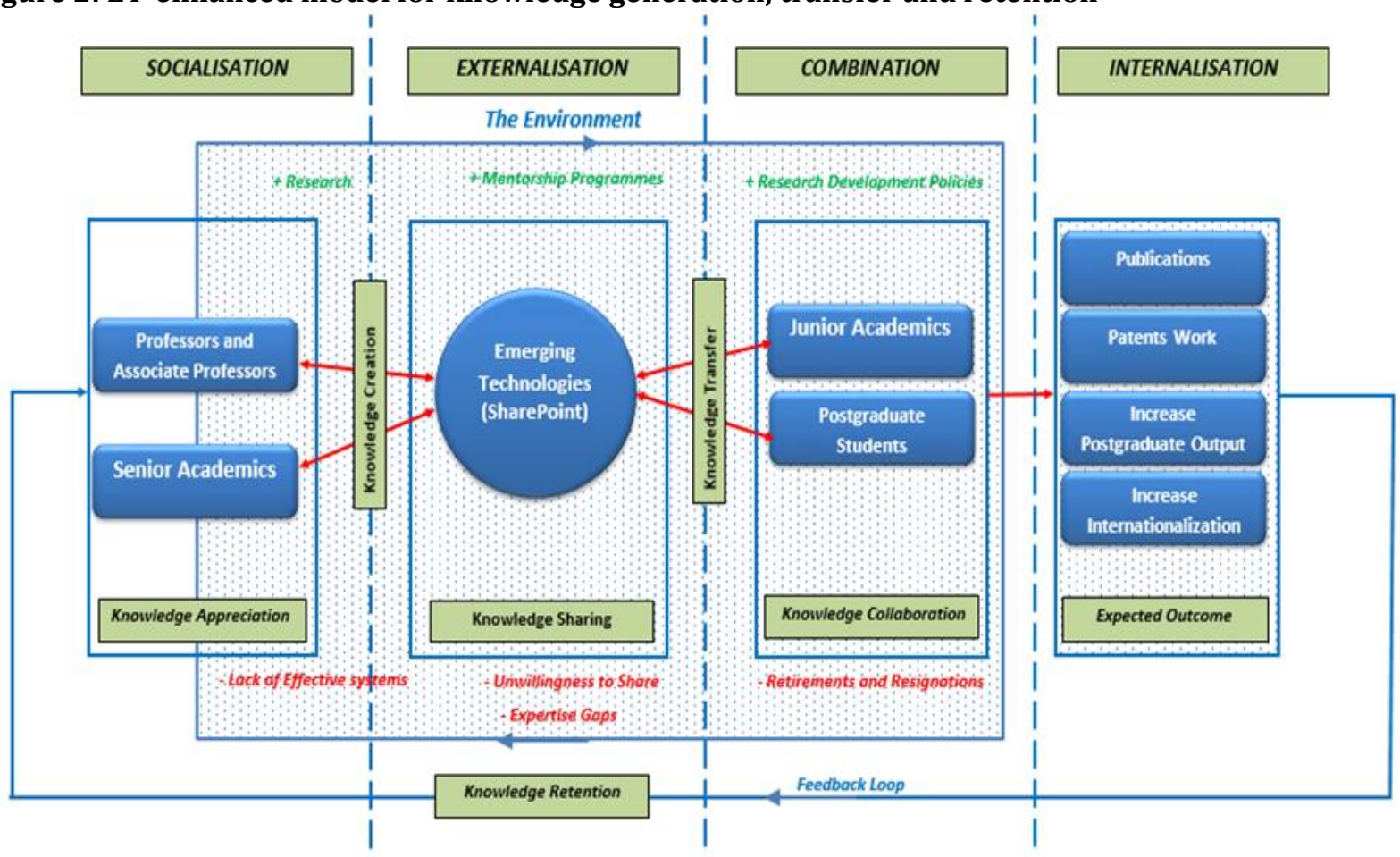

Source: Authors' compilation

Knowledge appreciation stage is an equivalent of Nonaka \& Takeuchi's (1995) socialisation stage. In this stage, a seasoned researcher may create his/her personal internal or external blog where s/he experiments with his/her fuzzy, unrefined ideas, develop new insights and deploy them as triggersfor high-level thinking and deep learning. A typical example of knowledge appreciation is that Steven Downes and George Siemens 
employed personal blogs to explore and experiment with formative ideas leading to the formulation of Connectivism theory. A personal blog can be livestreamed and integrated into the SharePoint platform for easy accessibility by colleagues. As an external tool that is plugged into the university's SharePoint platform or university website, a personal blog becomes an excellent tool for thought leadership positioning (Pande et al., 2013). It is at this stage that a clear definition of roles and responsibilities in the knowledge management becomes critical to both the experienced researcher and novice's fulfillment of their duties. Knowledge creation involves enactment, negotiation, documentation of knowledge or conversion of information into knowledge. In this stage, an organisational memory is formed by refining, organising, and storing knowledge using structured content repositories and data warehouses (Pande et al., 2013). In SharePoint, senior academics can create knowledge through 'crowd sourcing' and synthesis of ideas from various literatures, the development of scholarly manuscripts and their archiving on this platform. Senior academics can also generate knowledge through collaborative authorship with their experienced peers or with their novice researchers serving as research assistants. This stage can be conceived as the first phase of Nonaka \& Takeuchi's (1995) knowledge externalisation process (see Nonaka \& Toyama, 2007).

Knowledge sharing may take different forms such as the exchange of explicit knowledge through formal presentations such as lectures, seminars and talks. Alternatively, it may involve the sharing of uncodified research experiences, repertoires and social practices, which triggers the externalisation of tacit research knowledge. This highly personal and hard to formalise research knowledge comprises insights, hunches and intuitions (Dave et al., 2012), which senior academics may possess but find hard to communicate to junior academics. Senior academics' informal offline conversations with novice academics may also provide the platforms through which such knowledge can be negotiated and shared collaboratively. This is externalisation of knowledge (Nonaka \& Takeuchi, 1995) may also involve junior academics' critical commentary of senior academics' draft manuscripts, work in progress, working papers and position papers via SharePoint features, which emphasise document management, collaboration, engagement and argument development. Knowledge sharing may also take the form of social bookmarking, where both senior and junior researchers save the links of relevant web resources they want to share or access in future. Overall, a combination of knowledge creation and sharing constitutes the knowledge externalisation process (Nonaka, Byosiere, Borucki \& Konno, 1994).

Knowledge transfer involves the extraction of knowledge from the knowledgeable knower (or experienced researcher) to the potential knower (or novice researcher) through various processes such as coconstruction of knowledge, scaffolding processes, direct instruction and mentoring. It relates to the sharing or communicating of knowledge (Szulanski, 1996; Wang \& Noe, 2010) through processes such as social interaction and intimate communication (Burmeister \& Rooney, 2015). To the extent that knowledge transfer in research knowledge production processes happens among potentially different generations and age groups, it may unfold in SharePoint through direct instruction, mentoring, narrating case studies and interactive digital storytelling by the experienced researchers. The knowledge transfer processes can also take practical forms such as division of labour in the write up of draft manuscripts, simulations of article writing and knowledge sharing processes in critical reading groups. The process of knowledge transfer demands a culture that prohibits or minimises hiding knowledge internal and external to the organisation and ensures unrestricted access to information (Esterhuizen, Schutte \& du Toit, 2012). Collectively, the knowledge transfer and collaboration phrases (see Figure 2) will form the knowledge combination phrase of Nonaka \& Takeuchi's model (Nonaka et al., 1995).

Knowledge retention emphasises knowledge management practices and processes designed to preserve [senior] or older workers' valuable organisational knowledge before they retire (Burmeister \& Rooney, 2015). The preservation of knowledge is intractably connected to its transfer without whom such preservation is untenable. At the core of knowledge retention is not only the transfer or exchange part (the responsibility of the knowledgeable knower) but rather authentic learning, de-learning and re-learning, which are precisely the responsibility of the potential knower (that is, the novice). As Rule (2006) suggests, the main dynamics of authentic learning are (1) encountering (close approximations of) real world problems, (2) using higher order thinking skills, (3) communicating between members of a community of learners, and (4) empowering novices to choose their own learning pathways. In the context of SharePoint, authentic learning processes may take deliberative, transactive and collaborative characters. Deliberative engagement 
may involve Socratic dialogues where experienced knowers and novices engage in question-based debates requiring deep thinking and critical questioning of concepts and issues. Such engagement lies at the level of conception of research ideas and their application in context. The transactive part may involve team building and group work that give rise to draft manuscripts while the collaborative component underlies taking collective responsibility for the final drafts, responding to reviewer comments and finalising the drafts.

Expected outcome involves the conversion of explicit knowledge into tacit knowledge, which is referred to as internalisation, which is closely related to 'learning by doing' (Nonaka \& Takeuchi, 1995). The approach/ model in Figure 2 illustrates the environment (academic world), where senior academics interact with the junior academics and postgraduates. In this environment, knowledge is firstly generated and afterwards transferred, notwithstanding the various obstacles that stand in the way of knowledge transfer. Some of these obstacles in the environment such as ineffective knowledge transfer systems can be addressed by the effective utilisation of the emerging technologies. Overall, the activities in knowledge creation environment which involve; knowledge appreciation, creation, sharing, transfer and retention are expected to yield various outcomes already indicated in the previous subsections of this study. Created explicit knowledge is shared throughout an enterprise and converted into tacit knowledge by individuals as they embody it (Nonaka \& Takeuchi, 1995). It is through the process of novices' internalisation of research knowledge, research repertoires and hunches that knowledge retention unfolds.

Research policy implications for knowledge management: Since the challenge of ineffective knowledge transfer systems can compromise the sharing of knowledge and that ETs could catalyze knowledge transfer processes, CUT's research development and innovation policy should clearly stipulate and monitor the place and role of ETs in knowledge sharing and transfer. To the extent that emerging technologies are hailed as important web-based tools for increased collaboration, innovation, participation and knowledge sharing (ElSayed \& Westrup, 2011; Mihai, 2014), such technologies should be integrated into this policy to ensure their holistic use in the entire knowledge management process at the institution. The culture of knowledge hiding and subtle reluctance of senior academics to mentor novices could be addressed through the strict enforcement of performance management policy targets that require senior academics to mentor and produce tangible research outputs with junior staff. These mentorship programs should include jointproduction of articles in high impact journals, write-up of book chapters published by esteemed publishing houses, and presentation of papers in high profile conferences in various disciplines. Although the Scholarship of Teaching and Learning Programme is an incredible institutional research intervention in this direction, joining this program is not compulsory, enforcement of targets is weak and many faculties are poorly represented on the program. The Star of Academe and Research Policy could be the critical vehicle through which research-based career succession could be forged. The integration of career succession planning into this policy at senior academic levels could be critical to addressing the expertise gaps and early retirements alluded to in Figure 2. The consideration and training of young academics with high potential to fill senior academic positions would be critical to building the requisite critical mass of research at CUT. Such shadowing could include joint preparation, write up and production of publications and co-supervision at postgraduate levels to improve research productivity.

Implications of share point-based knowledge management model for knowledge retention: Since the knowledge appreciation stage sets the tone for the articulation of tacit knowledge conveyed through research insights, hunches and difficult-to-communicate research repertoires, the seasoned researcher's articulation ability and the novice's appreciation of such tacit knowledge are key to the effective socialisation of the novice into the knowledge management process. Once people with the appropriate knowledge have been identified, they must be able to convey that knowledge, as tacit knowledge cannot be captured if it remains in the head of the knower (Esterhuizen et al., 2012). Therefore, although seasoned research practitioners may rely on craft knowledge to solve complex problems, they need to have important communication skills to articulate such knowledge just as the novice should not simply accumulate the knowledge but have an appreciation of how it is used in the framing and reframing of real life problems and testing out of real solutions (Calderhead \& Shorrock, 2005; Rambe \& Mawere, 2011). Knowledge appreciation demands epistemological access, which is not just about possessing the knowledge but knowing how to make it (i.e. the values, attitudes and practices that go into its making) (Rambe \& Mawere, 2011; Boughey, 2014). Knowledge appreciation stage demands expertise-in-context, which entails the articulation of non-deliberative behaviour 
along with its non-conceptual and embodied character (Boyd \& Addis, 2011).

Knowledge creation requires the knower to possess information sourcing and synthesis abilities to ensure seamless integration and conversion of information into knowledge. The synthesis and processing of the information collected are considered to be critical steps in the creation phase of the knowledge management theory (Nonaka, Byosiere, Borucki \& Noboru Konno, 1994; Agile Innovation, 2010). That said, for the experienced researcher, the synthesis of knowledge may be a consequence of individual conceptualisation and reflection, while for the novice researcher, interaction with the experienced knower is key to her ability to create new knowledge. The synthesis of research knowledge may be an outcome of dialectic intercourse in temporary and multi-faceted dialogues where participants can express their own ideas freely and openly, affirming and negating these in mutually constructive ways (Agile Innovation, 2010). Knowledge creation also depends on the enactment, and retrievability of the tacit knowledge. The usability, accessibility and familiarity of low cost, ubiquitous, threshold technologies such as SharePoint to the novice and the experienced researcher are also pivotal to knowledge creation and overcoming of organisational amnesia.

Knowledge sharing demands mutual trust and open communication between experienced researchers and the novices. Trust and open lines of communication are closely related to fostering strong personal relationships (Argote \& Ingram, 2000; Esterhuizen et al., 2012). Mutual trust implies that the novices believe in the capacity of the knowledgeable knower to articulate knowledge while the knowledgeable knower also holds the conviction that the potential knower (novice) will apply critically and genuinely the knowledge s/he (the knowledgeable knower) has articulated. This means the research expert should give the novice the 'benefit of the doubt' that he/she will demonstrate research integrity (e.g. through proper acknowledgement of the expert's work and desisting from plagiarism) and has an ability to become a research authority in her own right. Yet mutual trust also depends on the existence of a shared practice and understanding of the domain in which knowledge is shared and exchanged (Wenger, 1998; 2004; Rambe \& Mlambo, 2014).

The transfer of research knowledge demands the senior academic/researcher to desist from hiding knowledge by increasing the levels of knowledge accessibility to the novices. The journey to the externalisation of knowledge should support a culture that prohibits knowledge hiding within and beyond the organisation (Esterhuizen, et al., 2012). If tacit knowledge remains unspoken and hidden (McInerney, 2002), such knowledge which emerges from the assumptions and expertise of individuals that develop over years, may never be documented or recorded (Martins \& Martins, 2011). The transfer of knowledge also demands an alignment of the technology in use, the transfer strategy and the individuals affecting such transfer. Therefore, co-operating individuals should draw on available, low-cost technologies such as SharePoint, to develop an effective knowledge transfer strategy that draws on context relevant content in situated learning environments.

Knowledge retention requires not only organisational learning but also the re-hiring of senior academics who have already retired. With regard to organisational learning, the development of intergenerational teams may foster the reciprocal transfer of knowledge and enable less experienced workers to function as catalysts in unlocking the knowledge base of experienced workers (Tempest, 2003; Burmeister \& Deller, 2016). Ropes (2014) identify age-diverse teams as one of the effective mechanisms for advancing intergenerational learning. In academic settings, this may take the form of inter-and cross-generational research collaboration groups and group mentoring through mixed-age groups. Ebrahimi, Saives \& Holford (2008) conceive intergenerational management of knowledge to depend on the organisation's knowledge strategy, its information management systems and knowledge transfer processes, its employees' places of socialisation and communication networks. Levy (2011), however, emphasises effective human development strategies (e.g., shadowing, mentoring/ coaching, training) and leadership style, trust, organisational learning culture as the backbones of intergenerational transfer of knowledge.

\section{Conclusion and Future Research}

This paper revealed that knowledge transfer and retention are critical to the effective management of tacit research knowledge and increased research productivity of the university. Identifying with Mohayidin, Azirawani, Kamaruddin \& Margono, (2007), we argued that the unspoken and undocumented tacit 
knowledge is the most valuable strategic asset of UoTs, young universities with a limited tradition of high profile, scholarly research. The paper also argued that since tacit knowledge is inexorably difficult to articulate, inexpensive, ubiquitous digital platforms such as SharePoint, where senior academics and young academics congregate and deliberate on research matters, may serve as useful arenas for the externalisation of tacit research knowledge.

Mindful of the inter-generational knowledge and technology exposure gaps between aging academics (professors and senior researchers) and novice researchers, collaborative academic engagements in traditional web-based technologies which both groups are familiar with and exposed to (e.g. blogs, wikis) could serve as a springboard for the use of SharePoint. We proposed the seamless integration of these technologies through content aggregation tools such as notifications, RSS feeds and other content aggregators. That said, the appropriate integration of robust knowledge transfer and retention strategies, dedicated academic groups and appropriate, low cost, low threshold technologies would guarantee effective transfer of tacit research knowledge from experienced academics to novice researchers.

The success of the proposed knowledge transfer and retention model depends on a multi-pronged strategy of human resource development and talent retention founded on intergenerational training, creation of agediverse knowledge sharing teams, re-hiring of retired senior researchers (such as professor emeritus) on contract basis, promoting organisational learning, desisting from counterproductive practices such as knowledge hiding and eliminating systemic blockages to knowledge externalisation and sharing. Conscious of the fact that talent management can be a supplementary approach to addressing knowledge management challenges (Kumpirarusk, 2012); our model is located in strategies for advancing knowledge transfer and retention. While agreed succession plans with clear milestones can be used as mechanisms to groom novices and retain talented individuals, we are also mindful of the perilous effects of fast tracking junior, inexperienced researchers to senior positions prematurely without a corresponding level of research mastery.

\section{References}

Agile Innovation. (2010). Innovation and Knowledge Creation: (SECI) Framework for Organizational Knowledge Creation. Available at http://www.agileinnovation.eu/ [Accessed June 26, 2016]

Andersen, J. (2012). Protective capacity and absorptive capacity-Managing the balance between retention and creation of knowledge-based resources. The Learning Organization, 9(5), 440-452.

Argote, L. \& Ingram, P. (2000). Knowledge transfer: A basis for competitive advantage in firms. Organizational Behavior and Human Decision Processes, 82(1), 150-169.

Baban, C. F. (2007). A knowledge management approach in higher education. In: Proceedings of KSS'2007: The Eighth International Symposium on Knowledge and Systems Sciences, Japan Advanced Institute of Science and Technology, Ishikawa, November 5-7, 2007, 104-107.

Beazley, H., Boenisch, J. \& Harden, D. (2002). Continuity management-Preserving corporate knowledge and productivity: When employees leave. New York, NY: John Wiley \& Sons.

Boughey, J. D. (2014). A comprehensive university at the heart of its communities: establishing a framework for engagement. PhD Thesis. University of the Free State, Bloemfontein.

Boyd, D. \& Addis, M. (2011). Moving from knowledge management to expertise management: a problem of contexts. Working Paper Series, no. 3, Centre for Environment and Society Research. Birmingham City University, Birmingham.

Bozalek, V., Ng'ambi, D. \& Gachago, D. (2013). Transforming teaching with emerging technologies: Implications for Higher Education Institutions. South African Journal of Higher Education, 27(2), 419436.

Bozalek, V., Gachago, D. \& Watters, K. (2015). Twenty-first-century pedagogies: Portraits of South Africa higher educators using emerging technologies. In: V. Bozalek, D. Ng'ambi, D. Wood, J. Herrington and J. Amory, ed., Activity theory, authentic learning and emerging technologies: Towards a transformative higher education pedagogy $115-125.1^{\text {st }}$ Ed. New York: Routledge.

Burmeister, A. \& Rooney, D. (2015). Knowledge retention at work and aging. Encyclopedia of geropsychology. Singapore: Springer.

Burmeister, A. \& Deller, J. (2016). Knowledge Retention From Older and Retiring Workers: What Do We 
Know, and Where Do We Go From Here? Work, Aging and Retirement, 1-18.

Burch, R. F. \& Strawderman, L. (2014). Leveraging Generational Differences to Reduce Knowledge Transfer and Retention Issues in Public Administration. Public Administration Research, 3(2), 61-75.

Bussard, G. W. (2013). Knowledge Retention: Developing a Knowledge Transfer Plan for the Engineering Department at Wolf Creek Nuclear Operating Corporation. Master's dissertation, University of Kansas, United States.

Calderhead, J. \& Shorrock, S. B. (2005). Understanding Teacher Education: Case Studies in the Professional development of beginning teachers. Taylor \& Francis, London.

Calo, T. J. (2008). Talent management in the era of the aging workforce: The critical role of knowledge transfer. Public Personnel Management, 37, 403-416.

Carlie, P. \& Rebentisch, E. (2003). Into the black box: the knowledge transformation cycle. Management Science, 49, 1180-1195.

Carman, J. G., Leland, S. N. \& Wilson, A. J. (2010). Crisis in leadership or failure to plan: Insights from Charlotte, North Carolina. Non-profit Management Leadership, 21(1), 93-111.

Central University of Technology, Free State. (2014). Research and Innovation Report. Bloemfontein: Central University of Technology, Free State (CUT).

Chen, C. J. (2004). The effects of knowledge attribute, alliance characteristics, and absorptive capacity on knowledge transfer performance. Research and Development Management, 34(3), 311-321.

Chipunza, C. (2015). Research Committee 2015 Annual Report. Faculty of Management Sciences, Central University of Technology, Bloemfontein.

Dave, M., Dave, M. \& Shishodia, Y. S. (2012). Emerging Trends and Technologies in Knowledge management: A Holistic Vision. International Journal of Recent Research and Review, 3(1), 60-67.

De Jager, H. J. (2014). Progress report on Academic Plan Achievements - Academic Portfolio, Central University of Technology, Bloemfontein.

Dumay, J. (2015). Bridging the KM and IC divide: Academia vs. Practice? European Conference on Knowledge Management. Udine, Italy.

Du Pre, R. (2009). The place and role of universities of technology in South Africa. Bloemfontein: South African Technology Network.

Du Pre, R. (2010). Universities of technology in the context of the South African higher education landscape. In The Kagisano series. Universities of Technology - the deepening debate 1-41. Auckland Park: Council on Higher Education.

Durst, S. \& Ferenhof, H. A. (2014). Knowledge leakages and ways to reduce them in small and medium-sized enterprises (SMEs). Information, 5(3), 440-450.

Ebrahimi, M., Saives, A. \& Holford, W. D. (2008). Qualified ageing workers in the knowledge management process of high-tech businesses. Journal of Knowledge Management, 12, 124-140.

El Badawy, T. A., Marwan, R. M. \& Magdy, M. M. (2015). The Impact of Emerging Technologies on Knowledge Management in Organizations. International Business Research, 8(5), 111.

El-Sayed, H. \& Westrup, C. (2011). Adopting Enterprise Web 2.0 collaborative technologies in business: The implications for management accountants. Chartered Institute of Management Accountants.

Esterhuizen, D., Schutte, C. S. \& Du Toit, A. S. A. (2012). Knowledge creation processes as critical enablers for innovation. International Journal of Information Management, 32(4), 354-364.

Federkeil, G. \& Westerheijden, D. (2009). U - Multirank: Design and testing the feasibility of a Multidimensional Global University Ranking. Third International Conference on World-class Universities (WCU-3). 2-4 November, Shanghai, China.

Gates, B. (1999). Business @ the Speed of Thought Display: Using a Digital Nervous System. NY: Warner Books.

Johnson, L., Smith, R., Willis, H., Levine, A. \& Haywood, K. (2011). The Horizon Report 2011 3-6. Edition. Austin, TX: The New Media Consortium. Available at http://net. educause.edu/ir/library/pdf/HR2011.pdf [Accessed March 24, 2015].

Joshi, A., Dencker, J. C., Franz, G. \& Martocchio, J. J. (2010). Unpacking generational identities in organizations. Academy of Management Review, 35(3), 392-414.

Kang, J., Rhee, M. \& Kang, K. H. (2010). Revisiting knowledge transfer: Effects of knowledge characteristics on organizational effort for knowledge transfer. Expert Systems with Applications, 37(12), 1-6.

Kirsch, D. (2008). Knowledge Retention. Available at http://it.toolbox.com/wiki/index.php/ Knowledge_Retention [Accessed July 6, 2016]. 
Kumpirarusk, P. (2012). An analysis of knowledge management, competency and organizational characteristics affecting organizational performance of Thai universities: perspective of university administrators. (pp. 148-154). Ph.D Thesis. National Institute of Development Administration, Bangkok, Thailand.

Lategan, L. O. K. (2015). Research and Development Review Report to Senate. Central University of Technology. Bloemfontein: Central University of Technology.

Le Grange, L. (2003). Why publish. Perspectives in education, 21(2), 129-135.

Levine, K. J. (2008). Trait Theory, in A. Marturano and J. Gosling, Eds. Leadership: The Key Concepts, 163-166. Abingdon: Routledge.

Levy, M. (2011). Knowledge retention: Minimizing organizational business loss. Journal of Knowledge Management, 15, 582-600.

Liebowitz, J. (2008). Knowledge Retention: Strategies and Solutions. Boca Raton, London and New York: CRC Press, Taylor \& Francis Group.

Liebowitz, J. (2011). Knowledge retention: What practitioners need to know. Available at http://www.kmworld.com/Articles/Editorial/Feature/Knowledge-retention-What-practitionersneed-to-know-73363.aspx [Accessed July 8, 2016].

Linder, F. \& Wald, A. (2011). Success factors of knowledge management in temporary organizations. International Journal of Project Management, 29, 877-888.

Mangcu, X. (2014). Why are there so few black professors in South Africa? Available at https://www.theguardian.com/world/2014/oct/06/south-africa-race-black-professors [Accessed July 19, 2016].

Martins, E. C. \& Martins, N. (2011). The role of organisational factors in combating tacit knowledge loss in organisations. Southern African Business Review, 15(1), 2011.

Martins, E. C. \&Meyer, H. W. (2012). Organizational and behavioural factors that influence knowledge retention. Journal of Knowledge Management, 16, 77-96.

Mbeo, M. \& Rambe, P. (2016). Assessing the feasibility of a knowledge management model for research knowledge retention at a university of technology. In: A. Strasheim, A. Nel and E. Koekemoer (Eds.). Proceedings of the 28th Annual Conference of the Southern African Institute of Management Scientists (pp. 606-616). 4 - 7 September 2016, University of Pretoria

McInerney, C. (2002). Knowledge management and the dynamic nature of knowledge. Journal of the American society for Information Science and Technology, 53(12), 1009-1018.

McNair, D. E., Duree, C. A. \& Ebbers, L. (2011). If I knew then what I know now: Using the leadership competencies developed by the American association of community colleges to prepare community college presidents. Community College Review, 39(1), 3-25.

Mihai, A. (2014). Calibration of a Building Energy Model Using Measured Data for a Research Center. Master's dissertation. Concordia University, Montreal, Quebec, Canada.

Mohayidin, M. G., Azirawani, N., Kamaruddin, M. N. \& Margono, M. I. (2007). The Application of Knowledge Management in Enhancing the Performance of Malaysian Universities. The Electronic Journal of Knowledge Management, 5(3), 301-312.

Mthembu, T. (2014). Message from the Vice-Chancellor and Principal. In: Research and Innovation 2014 Annual Report. Central University of Technology, Bloemfontein.

National Plan on Higher Education's (NPHE). (2001). National Plan for Higher Education. Pretoria.

Neave, G. (1996). Homogenization, integration and convergence: The Cheshire cats of higher education analysis. In: Mockers and mocked: Comparative perspectives on differentiation convergence and diversity in higher education, 26-41. Edited by V. L. Meek, L. Goedegebuure and O. Kivinen, (Eds). Oxford: Pergamon.

Ngai, E. \& Chan, E., (2005). Evaluation of knowledge management tools using AHP, Expert Systems with Applications, 29, 889-899.

Ng'ambi, D. \& Bozalek, V. (2015). Introduction to emerging technologies. In: Activity theory, authentic learning and emerging technologies: Towards a transformative higher education pedagogy 105-114. Edited by V. Bozalek, D. Ng'ambi, D. Wood, J. Herrington and J. Amory, Ed., $1^{\text {st }}$ Ed. New York: Routledge.

Ng'ethe, N., Subotzky, G., Afeti, G. (2008). Differentiation and articulation in tertiary education systems: a study of twelve African countries. Washington, D.C.: World Bank.

Nonaka, I., Byosiere, P., Borucki, C. C. \& Konno, N. (1994). Organizational knowledge creation theory: a first 
comprehensive test. International Business Review, 3(4), 337-351.

Nonaka, I. \& Takeuchi, H. (1995). The knowledge-creating company. New York: Oxford University Press, 3-57.

Nonaka, I. \& Toyama, R. (2007). Why do firms differ? The theory of the knowledge-creating firm. In Knowledge creation and management 13-31. Edited by K. Ichijo, I. Nonaka (Eds.), Oxford University Press, New York.

Ntshoe, I. M. \& Selesho, J. M. (2014). Institutional ranking in a differentiated higher education in South Africa. South African Journal of Higher Education, 28(5), 1554-1574.

Pande, V. P., Yavatmal, B., Shelodkar, R. S. \& Khobragade, S. P. (2013). Emerging Technologies in Knowledge Management. Available at http://www.asmgroup.edu.in/incon/Incon-\%202013Journal/GENERAL\%20MANA-GEMNT/ INCON13-GEN-026.pdf[Accessed July 26, 2016].

Phaladi, M. P. (2011). Knowledge transfer and retention: the case of a public water utility in South Africa. Master's Thesis. University of Stellenbosch, Cape Town.

Price, M. (2016). Staff transformation at UCT. University of Cape Town News. Available at http://www.uct.ac.za/dailynews/?id=8752 [Accessed July 19, 2016].

Rahnavard, F. \& Mohammadi, A. (2009). Identification of Key Factors in Knowledge Management System's Success in Faculties and Higher Education Centres. Journal of IT management, 1(3), 37-52.

Rai, R. K. (2011). Knowledge management and organizational culture: a theoretical integrative framework. Journal of Knowledge Management, 15(5), 779-801.

Rambe, P. \& Mawere, M. (2011). Barriers and constraints to epistemological access to online learning in Mozambique schools. International Journal of Politics and Good Governance, 2(2.3), 1-26.

Rambe, P. \& Mlambo, S. (2014). Using digital storytelling to externalise personal knowledge of research processes: The case of a Knowledge Audio repository. The Internet and Higher Education, 22, 11-23.

Rao, R. (2002). Emerging Technologies in Knowledge Management. Paper presented at the Internet Librarian International Conference, March, 2002. London, UK.

Republic of South Africa. Department of Higher Education and Training (DHET). (2013). White Paper for Post-School Education and Training. Pretoria: Department of Higher Education and Training.

Republic of South Africa, Department of Higher Education and Training (DHET). (2015). Research Output Policy of the South African, Pretoria, Department of Higher Education and Training.

Rhodes, J., Hung, R., Lok, P., Lien, B. \& Wu, C. (2008). Factors influencing organizational knowledge transfer: Implication for corporate performance. Journal of Knowledge Management, 12(3), 84-100.

Richardson, M. (2011). A democratization of university rankings: U-Multirank. Research Trends (24), 9.

Robinson, G., Carrillo, P., Anumba, C. \& Patel, M. (2010). Governance and knowledge management for publicprivate partnerships. New York: John Wiley.

Ropes, D. (2014). Intergenerational learning in organizations: An effective way to stimulate older employee learning and development. Development and Learning in Organizations: An International Journal, 28, 7-9.

Rotman, D. (2013). How technology is destroying jobs. Technology Review, 16(4), 28-35.

Rowe, B. J. \& Widener, S. K. (2011). Where Performance Measurement and Knowledge Management Meet: Evaluating and Managing Corporate Knowledge. Journal of Accounting and Finance, 11(2), 91-106.

Rule, A. C. (2006). The components of authentic learning. Journal of Authentic Learning, 3(1), 1-10.

South African Technology Network (SATN). (2008). Final report on the project pertaining to the development of performance indicators for universities of technology (UOTs) and UOT-related parts of comprehensive universities (CUs). Bloemfontein, South African Technology Network.

Szulanski, G. (1996). Exploring internal stickiness: Impediments to the transfer of best practice within the firm. Strategic Management Journal, 17, 27-43.

Talebi, B. \& Galekandi, K. V. (2013). Knowledge Management Application in Research Management. Life Science Journal, 10(3), 124-130.

Tempest, S. (2003). Intergenerational learning: A reciprocal knowledge development process that challenges the language of learning. Management Learning, 34, 181-200.

Thomas, A. (2009). Knowledge retention strategies. Available at http://pmtips.net/knowledge-retentionstrategies/ [Accessed February 18, 2016].

Van Vught, F. (2007). Diversity and differentiation in higher education systems. Challenges for the knowledge society. Available at http://www.uhr.no/documents/Fran_van_Vught_text.pdf [Accessed July 25, 2016].

Wallis, J. (2003). Knowledge management in education; enhancing learning and education. E. Sallis and G. 
Jones (Eds.), Kogan Page London 2002.

Waghid, Y. \& le Grange, L. (2003). Research and development in higher education: rating or not? South African Journal of Higher Education, 17(1), 5-8.

Wang, S. \& Noe, R. A. (2010). Knowledge sharing: A review and directions for future research. Human Resource Management Review, 20, 115-131.

Wenger, E. (1998). Communities of practice: Learning, meaning, and identity. Cambridge, MA: Cambridge University Press.

Wenger, E. (2004). Communities of practice: An introduction. Available at http://www.ewenger.com/theory/index.htm [Accessed May 20, 2007].

Wilde, S. (2011). Customer Knowledge Management: improving customer relationship through knowledge application. Springer Science \& Business Media. Available at http://www.ebooksclub.org [Accessed June 2, 2016].

Zheng, W., Yang, B. \& McLean, G. N. (2010). Linking organizational culture, structure, strategy, and organizational effectiveness: Mediating role of knowledge management. Journal of Business Research, 63(7), 763-771. 